\title{
Effects of High Temperature on Carbonated Calcium Silicate Cement (CSC) and Ordinary Portland Cement (OPC) Paste
}

\author{
Warda Ashraf, Jan Olek, and Hyungu Jeong \\ Lyles School of Civil Engineering, Purdue University, West Lafayette, IN, USA \\ Vahit Atakan \\ Research and Development, Solidia Technologies, Piscataway, NJ, USA
}

\begin{abstract}
This paper presents a comparative study on the effects of high temperature $\left(\sim 500^{\circ} \mathrm{C}\right)$ on carbonated calcium silicate-based cement (CSC), hydrated ordinary Portland cement (OPC), and hydrated OPC with $20 \%$ fly ash (FA) paste samples. The CSC is primarily composed of calcium-silicate minerals with different calcium to silica atomic ratios, such as wollastonite, rankinite, and pseudowollastonite. The major difference between CSC- and OPC-based systems is that the CSC system generates strength from the carbonation reaction, while strength development of OPC-based systems depends on the hydration reaction. The microstructure of the carbonated CSC paste consist mainly of calcium carbonate, polymerized silica gel, and unreacted cement grains. The loss of stiffness due to the high-temperature exposure was found to be substantially lower for CSC samples compared with that of the hydrated OPC and OPC + FA paste samples. This observation was also consistent with the observed mass losses of these paste samples upon their exposure to high temperatures during the thermogravimetric analysis (TGA). The higher resistance of CSC paste samples to high temperature is attributed to the presence of microscopic phases which have higher decomposition temperatures than the phases present in the OPC. For the same reason, the increases in total porosities (measured using helium pycnometer) of the hydrated paste samples after exposure to $510^{\circ} \mathrm{C}$ were significantly higher than those of the CSC paste samples.
\end{abstract}

Keywords: viscoelasticity, DMTA, TGA, carbonation, porosity

\section{INTRODUCTION}

Conventional Portland cement-based materials are considered to be responsible for $5-8 \%$ of total manmade $\mathrm{CO}_{2}$ emissions. Due to this fact, finding an alternative cementitious system, with lower $\mathrm{CO}_{2}$ foot print than that of ordinary Portland cement (OPC), is one of the major challenges of cement and concrete industries. Accordingly, during the last decade, development of several alternative cementitious systems has been observed. Calcium silicate cement (CSC) is one of such alternative cementitious system (Sahu \& DeCristofaro, 2013), which was developed based on a US patent approved in 2015 (Riman et al., 2015). CSC cement is primarily composed of low-lime calcium silicates, such as wollastonite/ pseudowollastonite $\left(\mathrm{CaO} \cdot \mathrm{SiO}_{2}\right)$ and rankinite $\left(3 \mathrm{CaO} \cdot 2 \mathrm{SiO}_{2}\right)$ (Sahu \& DeCristofaro, 2013). These low-lime calcium silicates have a lower burning temperature (Engel'sht \& Muratalieva, 2013; Kaifi et al., 2004; Kotsis \& Balogh, 1989) than that of the conventional calcium silicate ingredients of OPC, i.e., tricalcium silicate $\left(3 \mathrm{CaO} \cdot \mathrm{SiO}_{2}\right)$ and dicalcium silicate $\left(2 \mathrm{CaO} \cdot \mathrm{SiO}_{2}\right)$. As a result, the production temperature of CSC $\left(\sim 1200^{\circ} \mathrm{C}\right)$ is $\sim 250^{\circ} \mathrm{C}$ lower than that of the OPC (Sahu \& DeCristofaro, 2013). Additionally, the amounts of limestone required to produce these low-lime calcium silicates are lower than those of OPC and hence also contribute to the reduction of $\mathrm{CO}_{2}$ emission from the calcination process involved in cement production. These low-lime calcium silicates are non-hydraulic but react with $\mathrm{CO}_{2}$ in the presence of moisture (Ashraf et al., 2015a; Bukowski \& Berger, 1978). Thus, the hardening and strength gaining processes in the CSC binder system involve the carbonation reaction of the calcium silicates which leads to effective binding of $\mathrm{CO}_{2}$ within the carbonation reaction products. This process is, therefore, essentially the same as that involved in "mineral carbonation" (Olajire, 2013). Combining the environmental benefits of low production energy requirement with those of the $\mathrm{CO}_{2}$ storage capability, the carbon footprint of CSC concrete is found to be $70 \%$ lower than that of OPC concrete (Sahu \& DeCristofaro, 2013).

To ensure long-term, successful application of this new material, both mechanical and chemical performances of this binder system need to be investigated. Previous research showed that this CSC binder can be used to produce concrete samples with compressive strength in the range of $55-80 \mathrm{MPa}$ 
(Jain et al., 2014). The freeze-thaw and scaling resistance of the concretes made using CSC binder system also showed to be very satisfactory (Jain et al., 2015). During the carbonation reaction, the CSC binder system forms calcium carbonate and a highly polymerized silica rich phase (also known as "calcium-modified silica gel") and calcium carbonate (Jain et al., 2014). The stiffness of this polymerized silica gel phase is also substantially higher than that of the calcium-silicate-hydrate $(\mathrm{C}-\mathrm{S}-\mathrm{H})$ gel, the primary binding phase of the hydrated OPC system (Ashraf et al., 2015b; Ashraf et al., 2015).

This paper focuses on a study of the effects of high temperature (up to $510^{\circ} \mathrm{C}$ ) on three different binder systems, namely: carbonated CSC paste, hydrated OPC paste, and hydrated OPC with fly ash (FA) paste samples. The specific objectives of this paper are to investigate how viscoelastic properties, mass, porosity, and microstructure of these paste samples are affected by the high-temperature exposure condition.

\section{MATERIALS AND METHODS}

Two different types of hydraulic binders were used in this study; the OPC and OPC with $20 \%$ FA (class - F) replacement. When preparing the pastes, the binders were first mixed with water (at water to cementitious material ratio $=0.4$ ) and then compacted into small bar molds (dimensions: $25.4 \mathrm{~mm} \times 25.4 \mathrm{~mm} \times 75 \mathrm{~mm}$ ). After $24 \mathrm{~h}$ of curing, these beam samples were removed from the molds and cured in lime saturated water for 65 days at $23^{\circ} \mathrm{C}$. The bar samples were then removed from lime saturated water and cut to obtain beam samples (with dimensions of $3 \mathrm{~mm} \times 10 \mathrm{~mm} \times 50 \mathrm{~mm}$ ) for testing in dynamic mechanical thermal analyzer (DMTA). Small block $(15 \mathrm{~mm} \times 10 \mathrm{~mm} \times 20 \mathrm{~mm}$, approximate dimensions) samples were also collected from the paste bars to measure their porosities. Additional paste samples were ground using mortar and pestle to obtain powders for TGA tests. The CSC paste bars (water to cement ratio $=0.3$ ) were prepared using the same procedure as that used for the OPC samples except, in this case, the bars were cured at $65^{\circ} \mathrm{C}, 70 \% \mathrm{RH}$, and $100 \% \mathrm{CO}_{2}$ concentration for $65 \mathrm{~h}$. Small paste beam and block samples were prepared from the carbonated CSC paste bars following the same cutting process as that used for the hydrated OPC and OPC + FA paste samples.

Both, the DMTA and TGA tests were performed using commercially available instruments (model Q800 and Q50 TA instruments were used for DMTA and TGA tests, respectively). Porosities of the paste samples were measured using $15 \mathrm{~mm} \times 10 \mathrm{~mm} \times 20 \mathrm{~mm}$ (approximate dimensions) paste blocks. Small sample dimensions were selected to ensure uniform heating throughout the sample. Permeable porosities [also known as re-saturation porosities (Day \& Marsh, 1988)] of the cement paste blocks were determined from their oven dry and saturated surface dry masses using Eq. 1:

$$
\text { Permeable porosity }(\%)=\frac{M_{S S D}-M_{O}}{M_{S S D}}
$$

Here, $M_{\mathrm{O}}$ is the dry mass after heating of the sample and $M_{S S D}$ is the mass of the same paste block in saturated surface dry (SSD) condition (after soaking it in deionized water for $24 \mathrm{~h}$ ). Total porosity of the paste samples were calculated from absolute and bulk densities using Eq. 2. Both densities were measured using helium pycnometer (commercial brand: AccuPyc II micrometrics). Utilization of a helium pycnometer ensures the measurement of total porosity as helium atoms have smaller dimension (i.e., diameter $=0.22 \mathrm{~nm}$ ) than that of the water molecules (i.e., diameter $=0.29 \mathrm{~nm}$ ).

$$
\text { Total porosity }(\%)=\left(1-\frac{\rho_{\text {bulk }}}{\rho_{\text {abs }}}\right) \times 100 \%
$$

Here, $\rho_{\text {env }}$ is the envelop density and $\rho_{\text {abs }}$ is the absolute density.

\section{RESULTS AND DISCUSSIONS}

\subsection{Mass change}

The traces of both, the TGA curves and their derivatives (DTG) for OPC, OPC + FA, and CSC paste samples are given in Figures 1 and 2, respectively. From these graphs, it can be observed that the mass loss at high temperature is much more rapid in OPC and OPC + FA cement pastes than in the CSC paste. For both, the OPC and OPC + FA samples, the mass loss peak at around $150^{\circ} \mathrm{C}$ (Figure 2 ) is due to the removal of evaporable water from gel and capillary pores and decomposition of ettringite and monosulphate phases. However, CSC paste, being a carbonation activated system, does not contain ettringite or monosulphate like phases. Moreover, the polymerization of gel phase present in CSC paste is much higher than that of the $\mathrm{C}-\mathrm{S}-\mathrm{H}$ present in OPC-based system (unpublished data from the ${ }^{29} \mathrm{Si} \mathrm{NMR}$ experiments.), which might have reduced the amount of evaporable gel water present in this system. Accordingly, the OPC and OPC + FA paste samples lost around 8 and $9.5 \%$ of original masses, respectively, within $200^{\circ} \mathrm{C}$. In case of CSC paste, mass loss within $200^{\circ} \mathrm{C}$ is only $1.5 \%$. Similarly, after $450^{\circ} \mathrm{C}$, the total mass loss of OPC and OPC + FA paste systems was found to be four to five times higher than that of the carbonated CSC paste (Figure 1). Irrespective of the mass loss associated 
with the gel phase, another primary microstructural phase of the hydrated systems, i.e., portlandite $\left[\mathrm{Ca}(\mathrm{OH})_{2}\right]$ decomposes at around $450-500^{\circ} \mathrm{C}$. On the other hand, the main carbonation reaction product of the CSC system, that is $\mathrm{CaCO}_{3}$, decomposes in the temperature range from 600 to $900^{\circ} \mathrm{C}$. Thus, evidently, CSC paste system can tolerate higher temperatures than that of the hydraulic binder based systems (i.e. OPC and OPC + FA pastes).

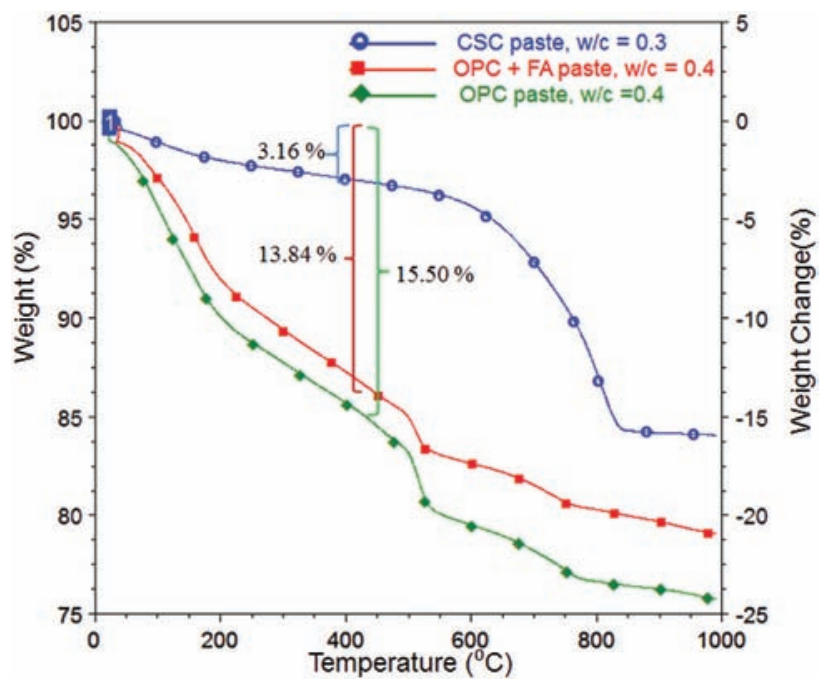

Figure 1. TGA graphs for OPC, OPC + FA, and CSC paste samples. Values within the graphs are the mass losses (\%) of the paste samples after exposure to $450^{\circ} \mathrm{C}$.

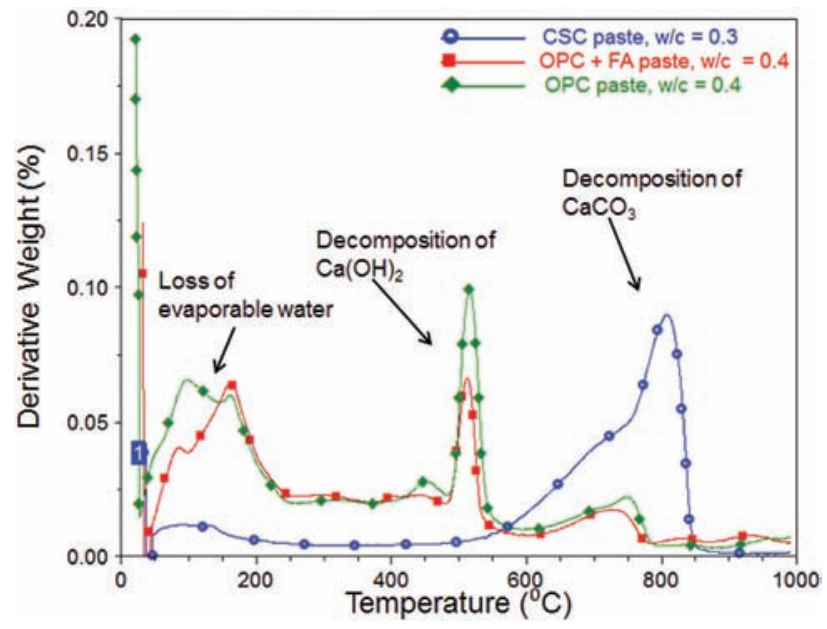

Figure 2. DTG graphs of the paste samples.

\subsection{Viscoelastic behavior of paste samples at high temperature}

The viscoelastic properties of the paste samples were measured using the DMTA test method. This test method was also used by several other researches to study conventional cement paste samples (Foray-Thevenin et al., 2006; Morlat et al., 1999). For the viscoelastic measurements, the paste samples were subjected to a dynamic load with $1 \mathrm{~N}$ peak force and $0.1 \mathrm{~Hz}$ frequency, while the temperature was increased at a rate of $3^{\circ} \mathrm{C} / \mathrm{min}$ (schematic of the experimental setup is given in Figure 3 ). The deflections of the samples were continuously monitored in the temperature range from $30^{\circ} \mathrm{C}$ up to $450^{\circ} \mathrm{C}$. The maximum allowable temperature for the equipment was $450^{\circ} \mathrm{C}$; and hence, this temperature was set as the upper limit of the test. The complex modulus $\left(E^{*}\right)$ was calculated from the stress amplitude and strain amplitude of the samples using Eq. 3. Complex modulus represents the stiffness of the samples.

$$
E^{*}=\left|\frac{\sigma_{A}}{\varepsilon_{A}}\right|
$$

Here, $\sigma_{A}$ and $\varepsilon_{A}$ are the stress and strain amplitudes, respectively (see Figure 4 ). The complex modulus $\left(E^{*}\right)$ or stiffness of the material is composed of the storage modulus $E^{\prime}$ and the loss modulus $E^{\prime \prime}$ (as shown in Eqs 4 and 5). Storage modulus measures the stored energy of the elastic portion, whereas the loss modulus represents the viscous portion.

$$
\begin{aligned}
& E^{\prime}=E^{*} \cos \delta \\
& E^{\prime \prime}=E^{*} \sin \delta
\end{aligned}
$$

Here, $\delta$ is the phase difference between the stress and strain of the material (see Figure 4).

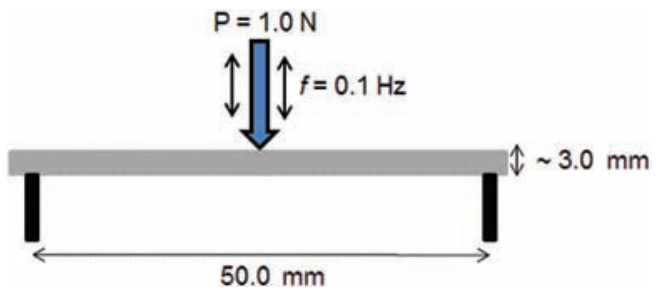

Figure 3. Schematic of the DMTA test setup.

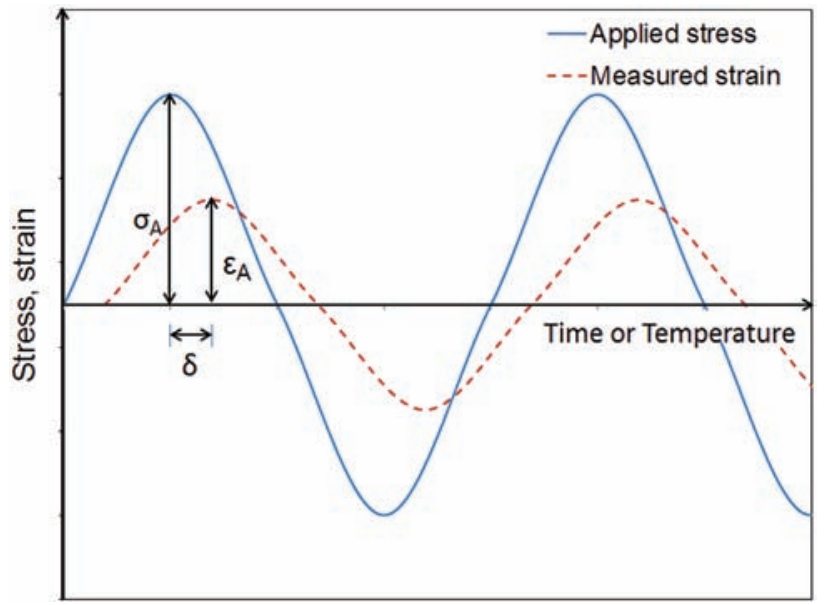

Figure 4. Schematic of the applied stress and response of a viscoelastic material. 
Figure 5 shows the variation of storage modulus and loss modulus of CSC paste samples within the temperature range of $30-450^{\circ} \mathrm{C}$. As it can be observed from this figure, there was a rapid decrease in the storage modulus of the sample up to about $200^{\circ} \mathrm{C}$, followed by a more gradual decrease up to $450^{\circ} \mathrm{C}$. The initial decrease in the storage modulus is attributed to the loss of the evaporable water. The subsequent gradual removal of the binding water from the gel phase might have caused the gradual decrease in the storage modulus of the CSC paste samples in the temperature range from $200^{\circ} \mathrm{C}$ up to $450^{\circ} \mathrm{C}$.

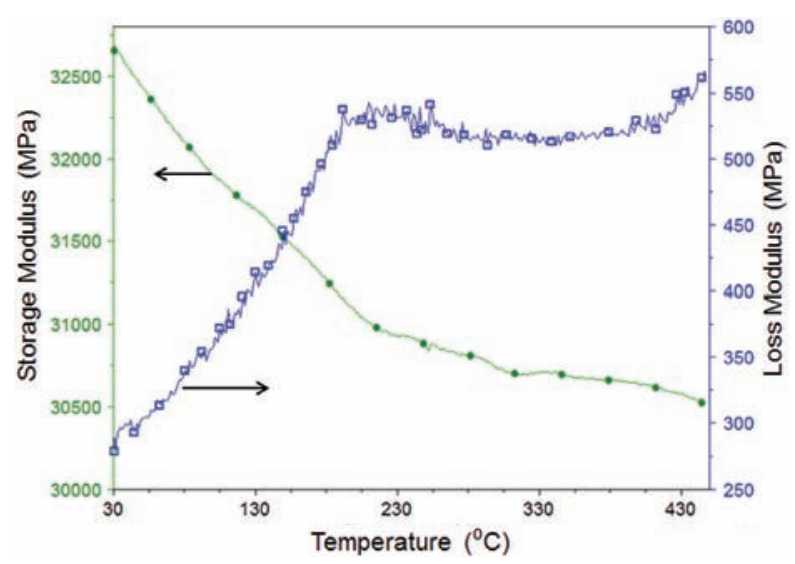

Figure 5. Storage modulus and loss modulus of CSC paste samples with increasing temperature.

The complex modulus $\left(E^{*}\right)$ incorporates the effects of temperature on both, storage modulus and loss modulus according to Eq. 6. Thus, in this article, the changes in complex moduli (i.e., stiffnesses) of the different paste systems while exposed to high temperature tests are compared (see Figure 6).

$$
E^{*}=\sqrt{\left[E^{\prime}\right]^{2}+\left[E^{\prime \prime}\right]^{2}}
$$

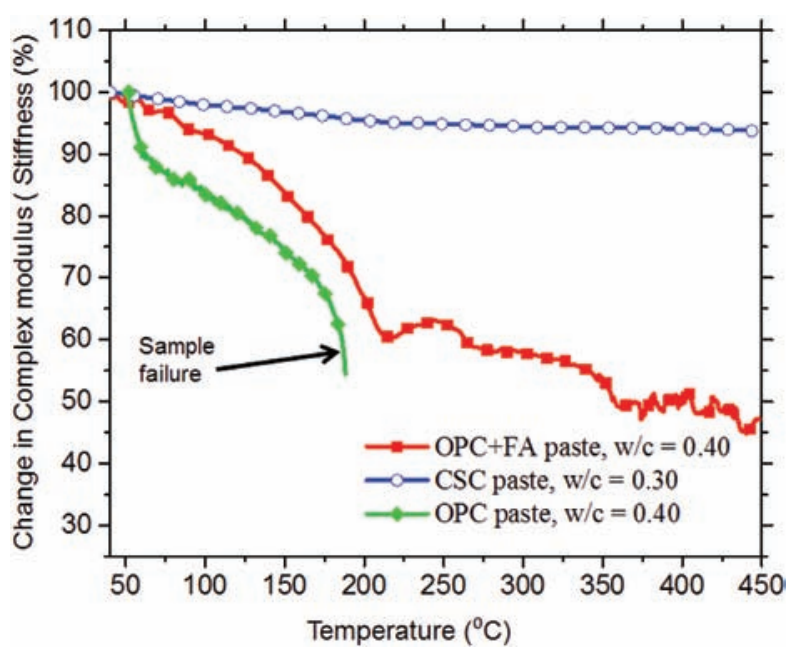

Figure 6. Changes in stiffness of the paste samples with increasing temperature.
In general, the trend of variations in stiffness (Figure 6) is very similar to weight change behavior (see Figure 1) as both, the loss of stiffness and loss of mass are due to the decomposition of the microstructural phases. From this Figure, it can be observed that the stiffness of CSC system exposed to a temperature up to $450^{\circ} \mathrm{C}$ got reduced by about $6 \%$ (associated weight change was about $3.16 \%$, Figure 1). In case of OPC + FA system, the stiffness reduced rapidly to about $60 \%$ of the original value during exposure in the temperature range from 30 to $200^{\circ} \mathrm{C}$. Moreover, the OPC paste sample failed even before reaching the temperature of $200^{\circ} \mathrm{C}$. This rapid decrease in stiffness of the hydrated paste sample is due to the decomposition of significant amounts of hydrated phases present in such systems. Although the OPC + FA paste sample survived exposure to the temperature as high as $450^{\circ} \mathrm{C}$, a series of "noise-like" fluctuations can be observed in the stiffness values after $375^{\circ} \mathrm{C}$. These fluctuations of the stiffness values are attributed to the decomposition of the $\mathrm{Ca}(\mathrm{OH})_{2}$ phase present in this system.

\subsection{Changes in porosities}

The changes (\%) in permeable and total porosities of the paste samples due to the exposure to high temperatures are given in Figures 7 and 8 , respectively. In both of these figures, for each of the paste samples, the porosity measured at $60^{\circ} \mathrm{C}$ was considered as a base (reference) porosity and any changes in porosities were calculated with respect to this value. It should be noted that different cement blocks were used to obtain each of the reported data points to avoid the effects of repetitive saturation and drying processes.

From Figures 7 and 8 it can be observed that the increases in both, the permeable and the total porosities of the hydrated pastes (i.e., OPC and OPC + FA pastes) were higher than those of the carbonated CSC paste. Interestingly, as shown in Figure 6, in case of hydrated paste samples, a significant decrease $(\sim 40 \%)$ in stiffness values was observed in the temperature range from 30 to $200^{\circ} \mathrm{C}$. However, in the same temperature range, the increases in both permeable and total porosity were less pronounced (below 20\%). This is rather unexpected and perhaps related to the fact that the decrease in stiffness within this temperature (i.e., $200^{\circ} \mathrm{C}$ ) is due to the rapid drying of the paste samples which might have led to the formation of some cracks in the hydrated paste samples but did not result in substantial increase in porosity. However, the porosities of the hydrated paste samples (OPC and OPC + FA pastes) increased substantially after exposure to a temperature of $510^{\circ} \mathrm{C}$ (due to decomposition of $\mathrm{Ca}(\mathrm{OH})_{2}$ ). Unfortunately, due to the temperature limitation (as mentioned earlier) of 
the DMTA equipment, the impact of these porosity changes on stiffness could not be captured. For both, the OPC and the OPC + FA paste samples, the increase

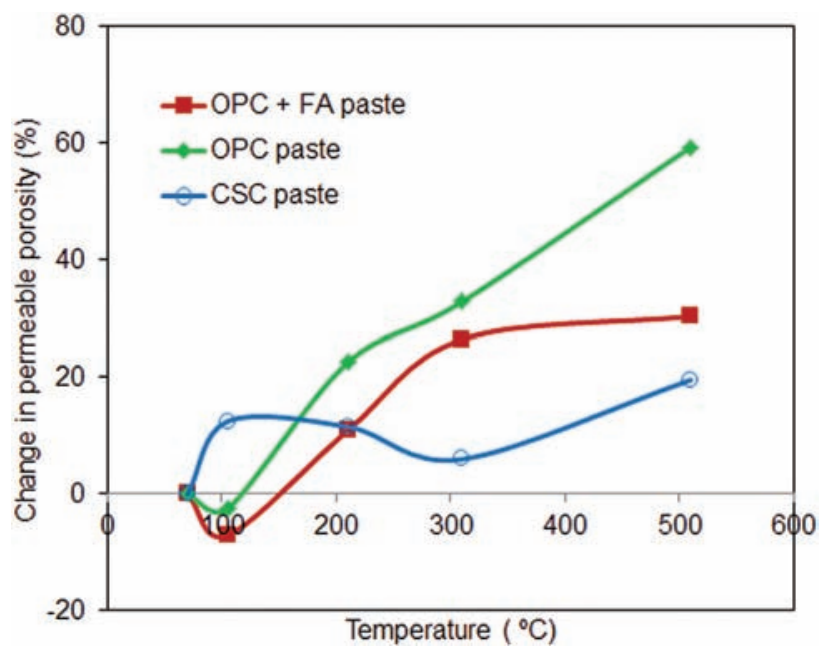

Figure 7. Changes in permeable porosities of the paste samples due to exposure to high temperature.

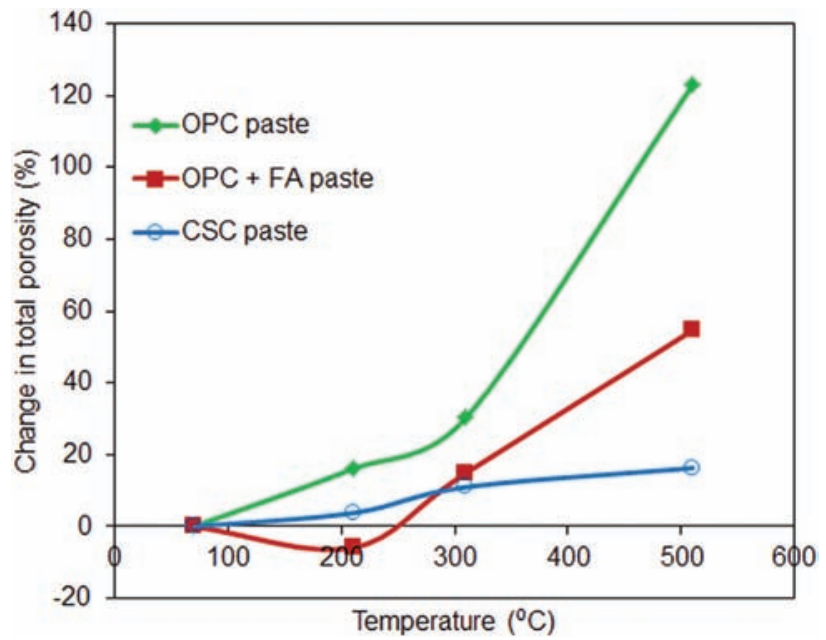

Figure 8. Change in total porosities of the paste samples due to exposure to high temperature.

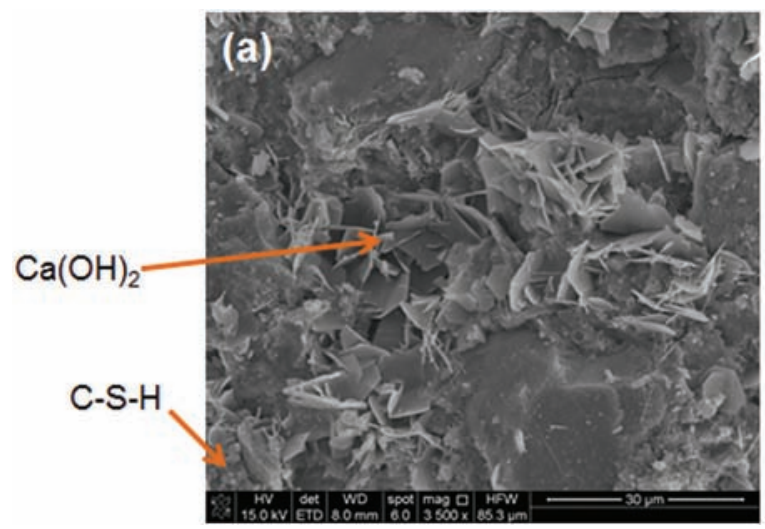

in total porosity after exposure to temperature of up to $510^{\circ} \mathrm{C}$ was higher than the increase in the permeable porosity. This indicates the formation of small pores (or cracks), which were not saturated with water even after $24 \mathrm{~h}$ of soaking. In case of carbonated CSC paste samples, the increases in both permeable and total porosities after exposure to a temperature of up to $510^{\circ} \mathrm{C}$ were $<20 \%$.

\subsection{Microscopic observations}

Figures 9-11 show the microscopic features of the pastes samples after exposure to temperatures of $60^{\circ} \mathrm{C}$ and $510^{\circ} \mathrm{C}$. The presence of $\mathrm{Ca}(\mathrm{OH})_{2}$, calciumsilicate-hydrate $(\mathrm{C}-\mathrm{S}-\mathrm{H})$, and ettringite phases was observed in OPC paste sample after it was exposed to $60^{\circ} \mathrm{C}$ [Figure $9(\mathrm{a})$ ]. In OPC paste sample exposed to $510^{\circ} \mathrm{C}$, plenty of major and minor cracks were observed in $\mathrm{C}-\mathrm{S}-\mathrm{H}$ like phases. There were no visible deposits of $\mathrm{Ca}(\mathrm{OH})_{2}$ or ettringite [Figure $9(\mathrm{~b})$ ]. In the case of the OPC + FA paste samples, abundant foil- or fiber-like ettringite depositions were identified [Figure 10(a)]. After exposure to $510^{\circ} \mathrm{C}$, the ettringite deposits appeared to have converted to needle-like residues. Cracks were also observed in and around the fly ash particles in specimens exposed to $510^{\circ} \mathrm{C}$ [Figure 10(b)]. In case of the carbonated CSC paste samples, no significant differences were observed between the microstructures of the paste samples exposed to the temperature in the range of $60-510^{\circ} \mathrm{C}$. However, the silica-rich gel phase which, in general, has been observed to have a honeycomb-like structure [Figure 11(a)] appeared to be slightly crumpling after exposure to $510^{\circ} \mathrm{C}$ [Figure $11(\mathrm{~b})$ ].

\section{CONCLUSIONS}

This paper presents the results of the investigation on the effects of high temperature $\left(\sim 500^{\circ} \mathrm{C}\right)$ on the newly developed carbonation activated binder (CSC paste) system and the conventional hydrated pastes. The following conclusions can be drawn from this study:

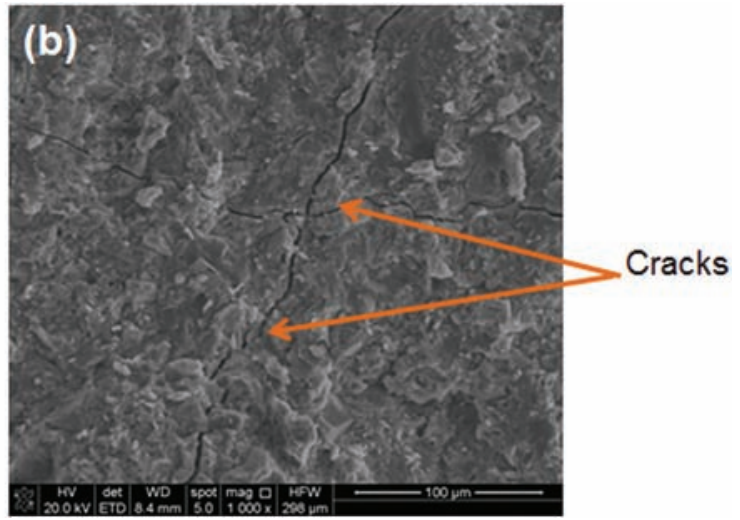

Figure 9. (a) $\mathrm{OPC}$ paste sample dried at $60^{\circ} \mathrm{C}$ showing hexagonal plates $\mathrm{Ca}(\mathrm{OH})_{2}$, (b) $\mathrm{OPC}$ paste sample exposed to $510^{\circ} \mathrm{C}$ showing cracks in the paste matrix. 

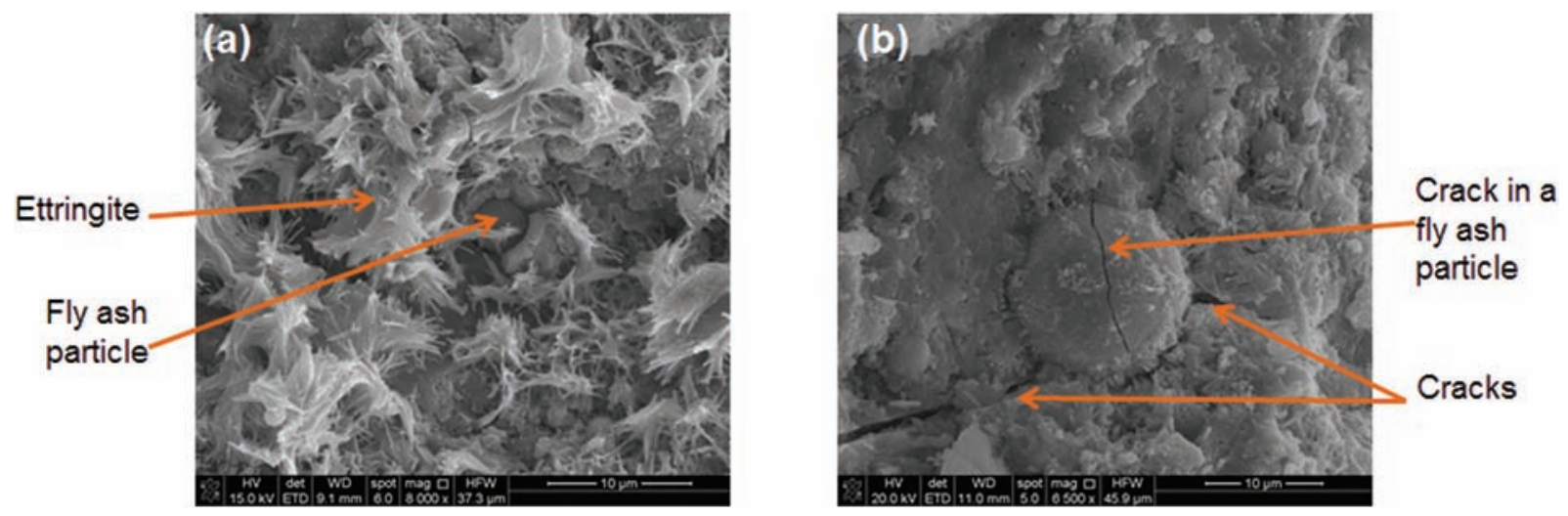

Figure 10. (a) OPC + FA paste sample dried at $60^{\circ} \mathrm{C}$ showing foil like ettringite phase, (b) OPC + FA paste sample exposed to $510^{\circ} \mathrm{C}$ showing cracks through and around the fly ash particle
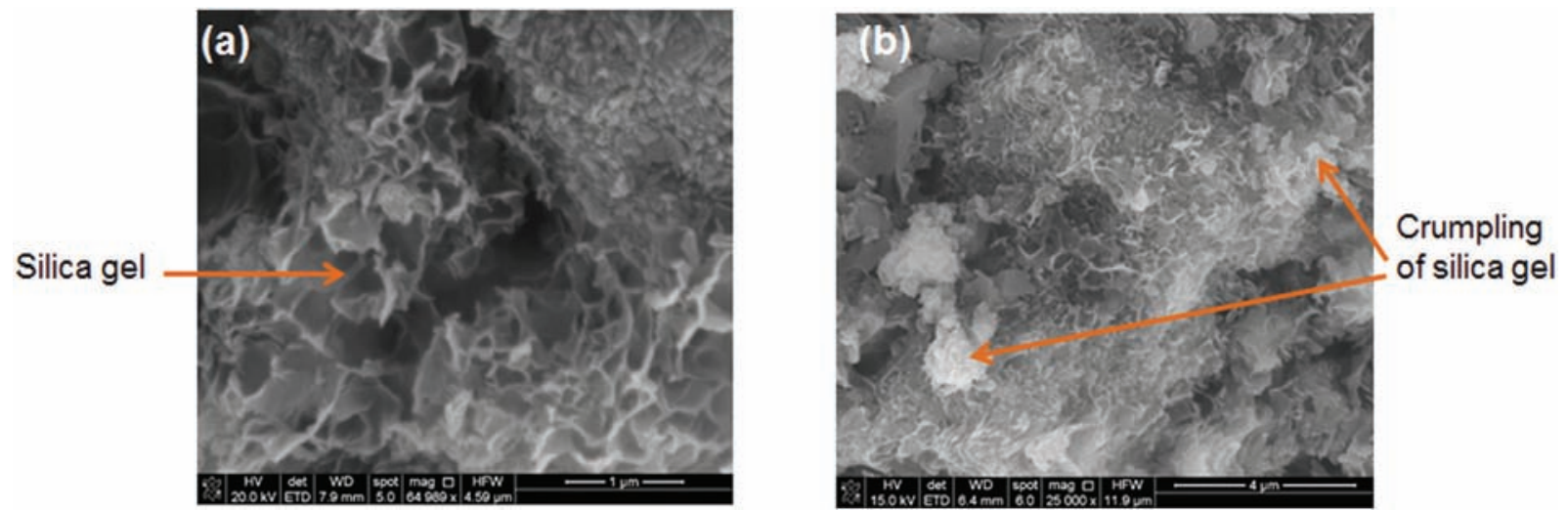

Figure 11. (a) CSC paste sample dried at $60^{\circ} \mathrm{C}$ showing honeycomb-like morphology of the silica rich phase, (b) CSC paste sample exposed to $510^{\circ} \mathrm{C}$ showing crumpling of the silica-rich gel phase

1. The decomposition temperatures of the microscopic phases present in the hydrated systems (OPC and OPC + FA) are lower than those of the carbonated binder (CSC) system. The hydrated cement matrix losses around $13-15 \%$ of the mass within the initial $450^{\circ} \mathrm{C}$. On the other hand, the mass loss observed in the CSC paste was only around $3 \%$ after exposure to the same temperature range.

2. The OPC paste samples failed in DMTA test after exposure to $210^{\circ} \mathrm{C}$. Although it did not fail, the OPC + FA paste sample lost around $60 \%$ of its stiffness after exposure to $450^{\circ} \mathrm{C}$. On the other hand, the carbonated CSC paste only lost around $6 \%$ of its stiffness after the exposure to a temperature of $450^{\circ} \mathrm{C}$.

3. After exposure to $510^{\circ} \mathrm{C}$, the increases in both, the water permeable and total porosities of hydrated OPC and OPC + FA pastes were substantially higher (about 30-100\%) in comparison to those in the CSC paste samples (about 20\%).

\section{REFERENCES}

Ashraf, W., Olek, J., \& Atakan, V. (2015a). A comparative study of the reactivity of calcium silicates during hydration and carbonation reactions. Proceedings of the 14th international congress on cement chemistry Beijing, China.

Ashraf, W., Olek, J., \& Atakan, V. (2015b). Chemomechanical comparison of the carbonation and hydration reaction products of synthetic tricalcium silicate $\left(\mathrm{C}_{3} \mathrm{~S}\right)$. Proceedings of the 11th brittle matrix composites (BMC) (pp. 11-21). Warsaw, Poland.

Ashraf, W., Olek, J., \& Tian, N. (2015). Nanomechanical characterization of the carbonated wollastonite system. Proceedings of the 5th nanotechnology in construction (NICOM 5) (pp. 71-77). Chicago, IL.

Bukowski, J. M., \& Berger, R. L. (1978). Reactivity and strength development of $\mathrm{CO}_{2}$ activated nonhydraulic calcium silicates. Cement and Concrete Research, 9, 57-68. 
Day, R. L., \& Marsh, B. K. (1988). Measurement of porosity in blended cement pastes. Cement and Concrete Research, 18(1), 63-73.

Engel'sht, V. S., \& Muratalieva, V. Z. (2013). Thermal interaction between limestone and silica. High Temperature, 51(6), 769-775.

Foray-Thevenin, G., Vigier, G., Vassoille, R., \& Orange, G. (2006). Characterization of cement paste by dynamic mechanical thermo-analysis. Materials Characterization, 56(2), 129-137.

Jain, J., Atakan, V., DeCristofaro, N., Jeong, H., \& Olek, J. (2015). Performance of calcium silicatebased carbonated concretes vs. hydrated concretes under freeze-thaw environments. Solidia Technologies, White Paper. Retrieved from: http://solidiatech.com

Jain, J., Deo, O., Sahu, S., \& DeCristofaro, N. (2014). Solidia Concrete ${ }^{\mathrm{TM}}$. Solidia Technologies, White Paper. Retrieved from: http://solidiatech.com

Kaifi, F. M. Z., Aurangzeb, M., Ahmed, B., \& Khan, M. (2004). Manufacture of synthetic wollastonite.
Journal of the Chemical Society of Pakistan, 26, $1-4$.

Kotsis, L., \& Balogh, A. (1989). Synthesis of wollastonite. Ceramics International, 15 , 79-85.

Morlat, R., Godard, P., Bomal, Y., \& Orange, G. (1999). Dynamic mechanical thermoanalysis of latexes in cement paste. Cement and Concrete Research, 29(6), 847-853.

Olajire, A. A. (2013). A review of mineral carbonation technology in sequestration of $\mathrm{CO}_{2}$. Journal of Petroleum Science and Engineering, 109, 364-392.

Riman, R. E., Nye, T. E., Atakan, V., Vakifahmetoglu, C., Li, Q., \& Tang, L. (2015). Synthetic formulations and methods of manufacturing and using thereof. US patent US 9216926 B2. Washington, DC.

Sahu, S., \& DeCristofaro, N. (2013). Solidia Cement $^{\mathrm{TM}}$. Solidia Technologies, White Paper. Retrieved from: http://solidiatech.com 